\title{
Evaluating Effects of an Oral Green Tea Extract, Polyphenon E, on Tissue Biomarkers, Using Re- verse Phase Protein Array in Women with Operable Breast Cancer
}

Ho KA ${ }^{1}$, Cardelli JA², McLarty J ${ }^{2}$, Hershman DL ${ }^{1}$, Maurer $\mathrm{M}^{1}$, Kalinsky $\mathrm{K}^{1}$, Hibshoosh $\mathrm{H}^{1}$, Su $\mathrm{T}^{1}$, Refice SF${ }^{1}$, Crew $\mathrm{KD}^{1 *}$

${ }^{1}$ Herbert Irving Comprehensive Cancer Center, Columbia University, New York, NY, United States.

${ }^{2}$ Louisiana State University Health Sciences Center, Shreveport, LA, United States.

\begin{abstract}
Experimental data support potential anti-tumor effects of green tea in breast cancer, yet limited data exists in human intervention trials. We conducted a phase 0 single-arm trial in women with newly diagnosed operable breast cancer given an oral green tea extract, Polyphenon E (Poly E), $800 \mathrm{mg}$ daily for at least 2 weeks prior to surgical resection. Among Poly E-treated cases and matched historical controls, changes in tumor protein expression from the diagnostic core biopsy (pretreatment) and surgical resection (post-treatment) were analyzed by immunohistochemistry (IHC) for Ki67 proliferation index, estrogen receptor (ER), progesterone receptor (PR), HER2, and reverse phase protein array (RPPA). From February 2008 to September 2009, 27 women were enrolled and 21 were evaluable. Median duration on Poly E was 20days (range, 13-36 days). We demonstrated significant correlations between IHC and RPPA for Ki67 ( $p<0.0001), E R$ ( $p=0.0017)$, and PR $(\mathrm{p}=0.0014)$. Poly E treatment did not cause a significant decrease in Ki67 compared to untreated controls (mean absolute change, $-0.5 \%$ vs. $+2.6 \%$; $\mathrm{p}=0.83$ ). The Poly E-treated group showed a significant change from baseline in PI3K/AKT pathway proteins, HSP90 clients, and Src/STAT activity. Compared to untreated controls, the Poly E group had significant down-regulation of PRAS40-pT246, MIG-6, and Src-pY416 and up-regulation of Notch1. Short-term administration of Poly E did not significantly decrease proliferation in breast tumor tissue; however, our RPPA data suggests that Poly E may act on alternative pathways. This is the first human intervention trial to demonstrate the biologic effects of Poly E on growth factor signaling in breast cancer.
\end{abstract}

Keywords: Biomarkers; Breast Cancer; Chemoprevention; Green Tea; Proteomics.

\section{*Corresponding Author:}

Katherine D. Crew MD MS,

Assistant Professor of Medicine and Epidemiology, Herbert Irving Comprehensive Cancer Center, Columbia University, 161 Fort Washington Ave, 10-1072, New York, NY 10032, USA.

Tel: $212-305-1732$

Fax: 212-305-0178

E-mail:kd59@cumc.columbia.edu

Recieved: February 08, 2015

Accepted: March 17, 2015

Published: March 19, 2015

Citation: Crew KD et al., (2015) Evaluating Effects of an Oral Green Tea Extract, Polyphenon E, on Tissue Biomarkers, Using Reverse Phase Protein Array in Women with Operable Breast Cancer. Int J Food Sci Nutr Diet. 04(2), 190-196. doi: http://dx.doi.org/10.19070/2326-33501500035

Copyright: Crew $\mathbf{K D}^{\odot}$ 2015. This is an open-access article distributed under the terms of the Creative Commons Attribution License, which permits unrestricted use, distribution and reproduction in any medium, provided the original author and source are credited.

\section{Introduction}

Breast cancer chemoprevention with anti-estrogens has been shown to reduce the incidence of estrogen receptor (ER)-positive tumors $[1,2]$, however, we have yet to identify effective chemopreventive agents for ER-negative tumors. A growing body of evidence suggests a potential chemopreventive effect of green tea in breast cancer. A recent meta-analysis, encompassing 5,617 breast cancer cases, reported an inverse association between green tea consumption and breast cancer incidence and risk of recurrence [3]. Experimental data have demonstrated the anti-cancer effects of the main component of green tea, epigallocatechin3-gallate (EGCG) [4]. In preclinical studies, the anti-tumor effects of EGCG on breast cancer cells were independent of ER status [5]. Proposed mechanisms of action of EGCG include downregulation of key cell signaling pathways in breast carcinogenesis, such as the PI3K/AKT pathway $[6,7]$. However, there is limited data on the target tissue effects of tea polyphenols in breast cancer from human intervention trials.

Polyphenon E (Poly E) is a well-defined pharmaceutical-grade decaffeinated green tea polyphenolic mixture, including $\sim 65 \%$ EGCG [8]. Each capsule contains 200mg of EGCG, which is equivalent to 2-3 cups of brewed green tea. In a phase I pharmacokinetic trial of Poly E $800 \mathrm{mg}$ daily (equivalent to 8-12 cups of green tea) given as a 4-week administration in healthy individuals, a $>60 \%$ increase in systemic levels of free EGCG was observed [9]. In human intervention trials, oral green tea polyphenols demonstrated chemo preventive activity in oral precancerous lesions [10], cervical lesions [11], high-grade prostatic intraepithelial neoplasia [12], colorectal adenomas [13], and Barrett's esophagus [14]. 
The high costs of large-scale chemoprevention studies have prompted the need for novel clinical trial designs, which use surrogate endpoints in lieu of cancer incidence in order to more rapidly screen promising chemopreventive agents. The phase 0 presurgical study design, in which patients with newly diagnosed operable cancer are given a short-term drug intervention prior to surgical resection, has been used for the early assessment of drugs for breast cancer treatment and prevention [15]. Advantages of this trial design include the lack of extra invasive procedures for tissue collection and the high yield from the directed core breast biopsies and surgical resections. Early changes in the proliferation marker, Ki67, within 2 weeks of treatment serves as a pharmacodynamic marker, which has been associated with long-term clinical outcomes $[15,16]$. We conducted a single-arm open-label trial of Poly E $800 \mathrm{mg}$ daily given for at least 2 weeks in 27 women with newly diagnosed operable breast cancer prior to surgery to measure tissue biomarker changes from the pre-treatment core breast biopsy to the post-treatment tumor resection.

\section{Materials and Methods}

\section{Study Population}

Twenty-seven women were enrolled at two sites: Columbia University Medical Center (CUMC) in New York, NY, and Louisiana State University Health Sciences Center (LSUHSC) in Shreveport, LA. Patients eligible for the trial were women, age 18 years or older, with histologically-confirmed invasive or non-invasive primary breast cancer on core breast biopsy and scheduled for surgical resection a minimum of 2 weeks after enrollment. Other inclusion criteria included an Eastern Cooperative Group (ECOG) performance status of 0 or 1 and normal hepatic and renal function. Patients were excluded if they had prior chemotherapy or hormonal therapy for breast cancer. Patients with a history of gastrointestinal bleeding, those who reported consumption of green tea within 1 week of breast biopsy or an allergy or intolerance to green tea were also not eligible. The study was approved by the institutional review board (IRB) at CUMC and LSUHSC prior to initiating enrollment. Participants provided signed informed consent in English or Spanish.

\section{Study Design and Intervention}

We conducted a multi-center, phase 0 , single-arm, open-label trial of presurgical administration of an oral green tea extract, Poly E, 800mg (4 capsules) daily for at least 2 weeks prior to breast surgery. Poly E (Polyphenon E International, Inc., New York, NY) is a purified tea fraction containing $80-98 \%$ total catechins by weight, with the main component being $\sim 65 \%$ EGCG. Poly E contains other catechins present at levels of $12 \%$ or below including epicatechin, epigallocatechin, epicatechingallate, and gallocatechingallate, as well as $<2 \%$ caffeine. Patients were instructed to take Poly E 4 capsules (800mg of EGCG) daily in the morning within 1 hour of a substantial meal and to continue until the day prior to breast surgery. The duration of drug administration varied between patients based upon their surgical schedule, median of 20 days (range, 13-36 days). The study drug was provided by the National Cancer Institute, Division of Cancer Prevention under an IND.

Safety and toxicity were assessed by monitoring clinical and laboratory parameters at baseline and the end of treatment. Adverse events were graded according to the National Cancer Institute Common Terminology Criteria for Adverse Events (NCI CTCAE), version 3.0. Safety was monitored by serum chemistries, hepatic panel, amylase and lipase. Study drug adherence was assessed by pill diaries and pill counts. Compliance was defined as taking at least $75 \%$ of the daily medications.

The primary study objective was to determine the tissue biomarker effects of Poly E. Tumor tissue biomarker changes from Poly E-treated cases were compared to archived tumor tissue from untreated historical controls matched $1: 1$ by age at diagnosis $( \pm 5$ years), breast cancer stage, tumor hormone receptor and HER2 status, and time interval between breast biopsy and surgery $( \pm 7$ days) from the Tumor Bank at CUMC. Pathologic characteristics including histologic type, grade, lymphovascular invasion, tumor size, nodal status, ER, progesterone receptor (PR), and HER2 expression were assessed according to standard guidelines [17] and obtained from pathology reports. Although a randomized placebo control group would have been ideal, this matched historical control group, which did not receive Poly E, provided a convenient reference group for biomarker comparisons with the Poly E-treated group.

\section{Biomarker Assays}

Formalin-fixed paraffin-embedded (FFPE) tumor tissue from the pre-treatment diagnostic core biopsy and post-treatment surgical resection were prepared for analysis of $\mathrm{Ki} 67$ by immunohistochemistry (IHC) at the Molecular Pathology Shared Resource at CUMC. Tissue samples for the Poly E group and matched historical controls were processed in a similar fashion, as per routine clinical care. In brief, 4- $\mu$ m sections cut from the FFPE tumor blocks were placed on positively charged slides, which following deparaffinization, were subjected to heat-induced epitope retrieval with proprietary buffer at $\mathrm{pH} 6.0$ (Trilogy), and immunostained using an automated immunostainer (DAKO, Carpinteria, CA) with the MIB-1 monoclonal antibody (1:200 dilution; DAKO, Carpinteria, CA) with known positive and negative controls. Ki67 proliferation index was expressed as percentage of positively staining cells among at least 500 neoplastic cells in randomly selected, high-power (x40) fields at the periphery of the tumor [18]. Ki67 score was determined by manual count (percentage of nuclear immunoreactivity of any intensity) by a single pathologist $(\mathrm{HH})$, blinded to case-control status and pre/post-treatment status.

Reverse phase protein array (RPPA) was performed at the M.D. Anderson Cancer Center Functional Proteomics RPPA Core Facility [19, 20]. Protein extracts from FFPE tumor blocks (ten 4- $\mu \mathrm{m}$ untreated slides) were prepared from appropriately isolated regions $(>70 \%$ tumor cells, as determined by an experienced pathologist $[\mathrm{HH}])$. Following deparaffinization, at least $30-40 \mu \mathrm{g}$ of protein per sample was extracted using an extraction buffer of 20 mMTris $\mathrm{HCl}$ buffer at $\mathrm{pH} 9$, with $2 \%(\mathrm{w} / \mathrm{v})$ SDS [21]. RPPA was conducted using a total of 161 antibodies (www.mdanderson.org/education-and-research/resources-for-professionals / scientific-resources / core-facilities-and-services / functional-proteomics-rppa-core/index.html), including markers of proliferation (PCNA) and apoptosis (e.g., cleaved caspase-3), as well as antibodies against EGFR, HER2, c-MET, IGF-1R, PI3K, PTEN, AKT, mTOR, and their phosphorylated isoforms. These antibodies have been fully validated by direct correlation between RPPA and Western blotting results. Specifically, tumor lysates were diluted in five 2-fold serial dilutions across multiple arrays 
and arrayed on nitrocellulose-coated slides (Whatman, Schleicher \& Schuell BioScience, Inc., Keene, NH). Samples were probed with validated primary antibodies and biotin-conjugated secondary antibodies and visualized by DAB colorimetric reaction [21]. Slides were scanned and quantified for raw signal intensities by using MicroVigene automated RPPA software (VigeneTech, Inc., North Billerica, MA) [19]. Dilution curves were fitted to the logistic model "Supercurve Fitting" (http://bioinformatics.mdanderson.org/OOMPA). Relative protein levels for each sample were derived from the supercurve for each lysate by curve-fitting, were normalized for protein loading [22], and the $\log 2$-scaled protein concentrations were normalized by global sample median normalization [23].

\section{Statistical Analysis}

The primary endpoint was change in Ki67 tumor expression before and after treatment with Poly E compared to untreated controls. Ki67 was log-transformed (lnKi67), as per recommendations from the International Ki67 in Breast Cancer Working Group [18]. Assuming a 7\% unevaluable rate, 50 of the 54 patients (27 Poly E-treated cases and 27 untreated historical controls) will be evaluable, giving us greater than $80 \%$ power to detect a 30\% decrease in $\ln \mathrm{Ki} 67$ from baseline, based upon a previously published presurgical study [16]. Patients were considered evaluable if they had sufficient pre/post-treatment tumor tissue for biomarker analysis.

Summary descriptive statistics and frequency distributions were used to describe the baseline characteristics of the Poly E-treated group and all biomarkers in the Poly E-treated and untreated groups. The RPPA spot signal intensity data from MicroVigene (Vigene'Tech, Inc.) was processed by the R package SuperCurve (version 1.01) [24]. Since the distribution of the original expression of the RPPA data was skewed, all statistical analyses were based on the $\log 2$ transformation of the original data [25]. Correlations between IHC and RPPA for ER, PR, HER2, and proliferation index were analyzed with Pearson correlation coefficient. Means and SDs were generated for all tissue biomarkers. Paired t-tests were used to evaluate within-group biomarker changes and two-sample t-tests to assess between-group differences. All tests were two-sided at $\mathrm{p}=0.05$ significance level. We also applied Bonferroni correction to adjust for multiple comparisons for the 161 RPPA markers using a conservative $\mathrm{p}$-value of 0.0003 . SAS software version 9.2 was used for all analyses (SAS Institute, Cary, NC).

\section{Results}

From February 2008 to September 2009, 27 women were enrolled and 21 were evaluable with sufficient pre/post-treatment tumor tissue for biomarker analyses. Unevaluable patients either had no residual tumor at the time of surgery or we were unable to retrieve the patient's pretreatment core breast biopsy from an outside hospital. Baseline patient and tumor characteristics for the evaluable participants are summarized in Table 1 . The median age was 49 years (range, 33-71). The majority was premenopausal (57\%), Hispanic $(62 \%)$, and had a body mass index $(B M I)$ of $25 \mathrm{~kg} / \mathrm{m}^{2}$ or

Table 1. Participant characteristics of Polyphenon E-treated group.

\begin{tabular}{|c|c|}
\hline Characteristics & Total $(n=21)$ \\
\hline Median age, years (range) & $49(33-71)$ \\
\hline \multicolumn{2}{|c|}{ Menopausal status, $n(\%)$} \\
\hline Premenopausal & $12(57)$ \\
\hline Postmenopausal & $9(43)$ \\
\hline \multicolumn{2}{|l|}{ Race, $n(\%)$} \\
\hline White & $7(33)$ \\
\hline Hispanic & $13(62)$ \\
\hline Black & $1(5)$ \\
\hline \multicolumn{2}{|l|}{ Body mass index, $n(\%)$} \\
\hline$<25 \mathrm{~kg} / \mathrm{m}^{2}$ & $7(33)$ \\
\hline $25-30 \mathrm{~kg} / \mathrm{m}^{2}$ & $6(29)$ \\
\hline$>30 \mathrm{~kg} / \mathrm{m}^{2}$ & $8(38)$ \\
\hline \multicolumn{2}{|l|}{ Stage, $n(\%)$} \\
\hline 0 & $3(14)$ \\
\hline $\mathrm{I}$ & $12(57)$ \\
\hline II & $4(19)$ \\
\hline III & $2(10)$ \\
\hline \multicolumn{2}{|c|}{ Breast cancer subtype, $n(\%)$} \\
\hline HR+ ductal carcinoma in situ & $2(9)$ \\
\hline HR- ductal carcinoma in situ & $1(5)$ \\
\hline HR+ HER2- invasive breast cancer & $16(76)$ \\
\hline HR- HER2+ invasive breast cancer & $1(5)$ \\
\hline Triple negative invasive breast cancer & $1(5)$ \\
\hline Median duration on Poly E, days (range) & $20(13-36)$ \\
\hline
\end{tabular}

Abbreviations: $\mathrm{HR}+$, hormone receptor positive (estrogen receptor (ER)+ and/or progesterone receptor (PR)+); HR-, hormone receptor negative (ER- and PR-); HER2, human epidermal growth factor receptor 2; triple negative (ER-, PR-, and HER2-) 
greater $(67 \%)$. Over half were diagnosed with stage I disease and three-quarters had hormone receptor-positive, HER2-negative invasive breast cancer. The median duration from diagnostic core biopsy to enrollment was 23 days (range, 11-64 days) and median duration on Poly E treatment was 20 days (range, 13-36 days). Compliance by pill count was $89 \%$ and Poly E was well-tolerated with no grade 2 or higher toxicities. The main grade 1 toxicities included headache $(n=4)$, dizziness $(n=3)$, and fatigue $(n=3)$.

Mean absolute Ki67 tumor expression by IHC at baseline for the Poly E-treated group and untreated group were 26\% (SD 24) and 19\% (SD 25), respectively. Overall, Poly E did not significantly change Ki67 proliferation index compared to untreated controls - mean absolute change in Ki67 of $-0.5 \%$ vs. $+2.6 \%$, respectively $(p=0.83)$ and mean proportional change of $\ln \mathrm{Ki} 67$ of $+1.1 \%$ vs. $+3.6 \%$, respectively $(\mathrm{p}=0.77)$. Next, we compared protein expression by IHC to RPPA for specific markers. There were significant correlations between IHC and RPPA for proliferation (correlation coefficient $\mathrm{r}=0.46, \mathrm{p}<0.0001), \mathrm{ER}(\mathrm{r}=0.45, \mathrm{p}=0.0017), \mathrm{PR}$ $(\mathrm{r}=0.46, \mathrm{p}=0.0014)$, and a trend for HER2 expression $(\mathrm{r}=0.28$, $\mathrm{p}=0.0923)$ (data not shown).

Among the 161 proteins evaluated, 54 demonstrated a significant change from baseline in the Poly E-treated group (see supple- mental Table), including components of the P13K/AKT, Src/ STAT, and apoptosis pathways, as well as HSP90 clients. When we applied a Bonferroni correction $(\mathrm{p}<0.0003)$ to adjust for multiple comparisons (Table 2), two PI3K/AKT pathway proteins (PRAS40-pT246, mTOR-pS2448), four HSP90 clients (HER2pY1248, CDK4, MEK1, MIG-6), and five Src/STAT activity proteins (Src-pY416, Src-pY527, p38-MAPK, MAPK-pT202-Y204, JNK2) showed a significant change from baseline in the Poly Etreated group at the conservative $\mathrm{p}$-value of $<0.0003$. The mean change from baseline in protein expression varied from -3.9459 to +0.4564 in the Poly E group. Significant biomarker changes also occurred within the untreated control group, where mean change from baseline ranged from -4.2374 to +0.9664 .

Comparing the Poly E-treated and untreated groups, only 4 proteins varied significantly from baseline, as shown in Figure 1. In the PI3K/AKT pathway, PRAS40-pT246 protein expression had a mean absolute change from baseline for the Poly $\mathrm{E}$ and untreated control groups of -0.1400 vs. -0.3126 , respectively $(p=0.0279$ ). For the HSP90 clients, there was down-regulation of MIG-6 by nearly 4-fold in the Poly E group compared to the untreated group $(-0.3573$ vs. $-0.0702, \mathrm{p}=0.0008)$. In the Src/STAT pathway, there was significant down-regulation of Src-pY416 with Poly E compared to no treatment, -0.3286 vs. $-0.1792(p=0.0428)$.

Table 2. Reverse phase protein array (RPPA)-generated protein expression in breast tumor tissue at baseline (pre-treatment) and at surgical resection (post-treatment) following the Polyphenon E (Poly E) intervention compared to untreated controls (paired tumor samples from matched historical controls who did not receive Poly E). Includes all protein biomarkers which had a significant change from baseline ( $p<0.0003$, based upon Bonferroni correction) in the Poly E-treated group or had significant differences in change from baseline $(\mathrm{p}<0.05)$ between the Poly E-treated and untreated control groups.

\begin{tabular}{|c|c|c|c|c|c|c|c|}
\hline \multirow{2}{*}{$\begin{array}{l}\text { Protein Bio- } \\
\text { marker }\end{array}$} & \multicolumn{3}{|c|}{ Poly E-treated group } & \multicolumn{3}{|c|}{ Untreated control group } & \multirow[b]{2}{*}{$\begin{array}{c}\text { P-value, } \\
\text { 2-sample } \\
\text { t-test }^{\mathrm{c}}\end{array}$} \\
\hline & $\begin{array}{l}\text { Mean protein } \\
\text { level at base- } \\
\text { line }^{\text {a }}(\mathrm{SD})\end{array}$ & $\begin{array}{l}\text { Mean protein } \\
\text { level at surgical } \\
\text { resection }^{\mathrm{a}}(\mathrm{SD})\end{array}$ & $\begin{array}{l}\text { P-value, } \\
\text { paired } \\
\text { t-test }^{\mathrm{b}}\end{array}$ & $\begin{array}{l}\text { Mean protein } \\
\text { level at base- } \\
\text { line }^{\mathrm{a}}(\mathrm{SD})\end{array}$ & $\begin{array}{l}\text { Mean protein } \\
\text { level at surgical } \\
\text { resection }^{\text {a }}(\mathrm{SD})\end{array}$ & $\begin{array}{l}\text { P-value, } \\
\text { paired } \\
\text { t-test }^{\mathrm{b}}\end{array}$ & \\
\hline \multicolumn{8}{|c|}{ PI3K/AKT pathway } \\
\hline PRAS40-p'T246 & $0.7703(0.0632)$ & $0.6289(0.0808)$ & $<.0001^{\mathrm{d}}$ & $0.9351(0.3472)$ & $0.6112(0.1109)$ & $0.0002^{\mathrm{d}}$ & $0.0279^{\mathrm{e}}$ \\
\hline mTOR-pS2448 & $0.3077(0.0500)$ & $0.2303(0.0392)$ & $0.0002^{\mathrm{d}}$ & $0.2832(0.0708)$ & $0.2320(0.0585)$ & 0.0045 & 0.1463 \\
\hline \multicolumn{8}{|c|}{ HSP90 Clients } \\
\hline HER2-pY1248 & $0.7387(0.1578)$ & $0.5255(0.0974)$ & $0.0001^{\mathrm{d}}$ & $0.5928(0.1749)$ & $0.4849(0.1167)$ & 0.0354 & 0.0744 \\
\hline CDK4 & $0.7461(0.4130)$ & $0.2923(0.1125)$ & $0.0002^{\mathrm{d}}$ & $0.6288(0.4713)$ & $0.3344(0.1662)$ & 0.0220 & 0.2006 \\
\hline MEK1 & $0.3725(0.1364)$ & $0.5398(0.1057)$ & $0.0002^{\mathrm{d}}$ & $0.4421(0.1892)$ & $0.5330(0.1103)$ & 0.0199 & 0.1382 \\
\hline MIG-6 & $0.7612(0.3202)$ & $0.4555(0.1952)$ & $0.0002^{\mathrm{d}}$ & $0.5076(0.1663)$ & $0.4425(0.0547)$ & 0.0652 & $0.0008^{\mathrm{e}}$ \\
\hline \multicolumn{8}{|c|}{ Src/STAT Activity } \\
\hline Src-pY416 & $0.9064(0.2800)$ & $0.5850(0.1683)$ & $<.0001^{\mathrm{d}}$ & $0.7035(0.1354)$ & $0.5139(0.1302)$ & 0.0007 & $0.0428^{\mathrm{e}}$ \\
\hline Src-pY527 & $0.5755(0.1500)$ & $0.2376(0.1069)$ & $<.0001^{\mathrm{d}}$ & $0.5357(0.3102)$ & $0.2304(0.1289)$ & 0.0029 & 0.5440 \\
\hline p38-MAPK & $0.5673(0.0754)$ & $0.6841(0.0901)$ & $0.0001^{\mathrm{d}}$ & $0.6256(0.1512)$ & $0.6581(0.0939)$ & 0.6116 & 0.0529 \\
\hline $\begin{array}{l}\text { MAPK-pT202- } \\
\text { Y204 }\end{array}$ & $0.3872(0.1160)$ & $0.2473(0.0685)$ & $0.0002^{\mathrm{d}}$ & $0.3763(0.1160)$ & $0.2258(0.0632)$ & $0.0001^{\mathrm{d}}$ & 0.7778 \\
\hline JNK2 & $0.6852(0.0953)$ & $0.8562(0.1304)$ & $0.0003^{\mathrm{d}}$ & $0.7379(0.1993)$ & $0.8513(0.1573)$ & 0.0282 & 0.2323 \\
\hline \multicolumn{8}{|c|}{ Other } \\
\hline Notch1 & $0.2776(0.0351)$ & $0.3053(0.0392)$ & 0.019 & $0.2872(0.0378)$ & $0.2780(0.0382)$ & 0.4094 & $0.0199^{\mathrm{e}}$ \\
\hline
\end{tabular}

${ }^{a}$ Relative protein levels for each sample were derived from the supercurve for each lysate by curve-fitting, were normalized for protein loading, and the log2-scaled protein concentrations were normalized by global sample median normalization.

${ }^{\mathrm{b}}$ Paired t-tests to evaluate within-group biomarker changes from baseline to surgical resection.

'Two-sample t-tests to assess differences in biomarker changes between the Poly E-treated and untreated control groups.

${ }^{\mathrm{d} S}$ tatistically significant after Bonferroni correction with a conservative p-value of $<0.0003$.

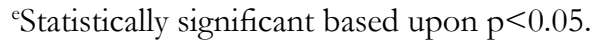


Figure 1. Percent change from baseline in mean reverse phase protein array (RPPA)-generated expression of selected proteins in the Polyphenon E-treated and untreated control groups.

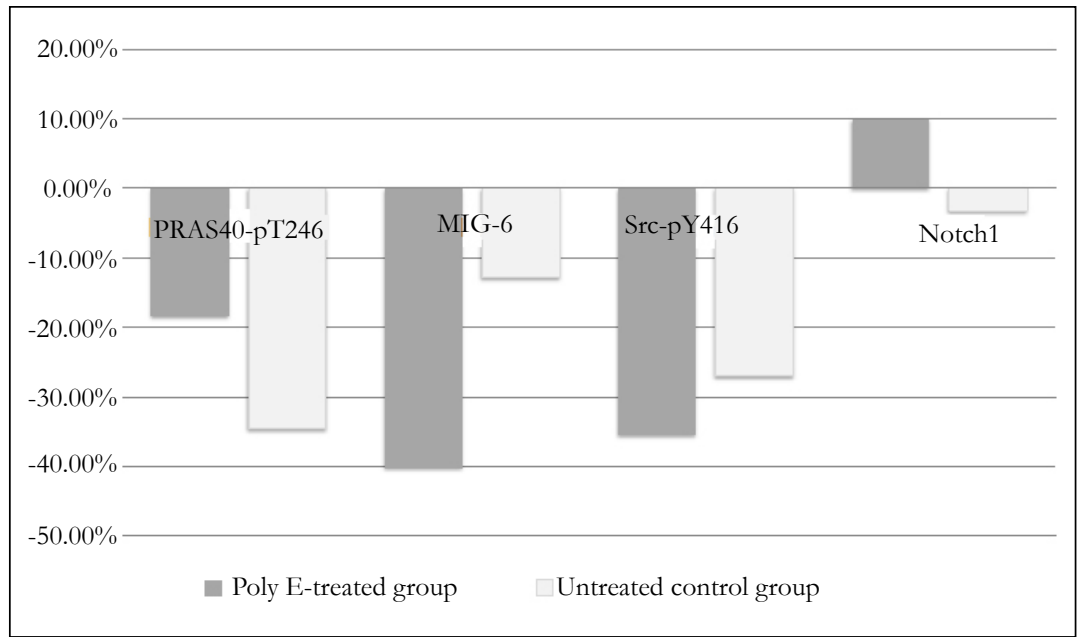

Abbreviations: PRAS40, proline-rich Akt substrate of 40 kDa; MIG-6, mitogen-inducible gene 6; Poly E, Polyphenon E; Src, steroid receptor coactivator

There was also significant up-regulation of Notch1 with Poly E compared to a slight decrease in untreated controls $(+0.0300$ vs $-0.0095, \mathrm{p}=0.0199)$. When we applied Bonferroni correction with a conservative $\mathrm{p}$-value of $<0.0003$, none of the changes in RPPA markers were statistically significant comparing the Poly E and untreated groups. The changes in protein expression of Notch1 in the Poly E-treated group were significant at $\mathrm{p}<0.05$, but not after Bonferroni correction. Although limited by the small sample size, no significant differences in biomarker effects were seen when the groups were stratified by menopausal status, Hispanic ethnicity, or BMI (data not shown).

\section{Discussion}

Overall, we did not observe a significant decrease in Ki67 tumor expression with short-term presurgical administration of the oral green tea extract, Poly E, in women with operable breast cancer. However, we did demonstrate significant modulation of 4 proteins in breast tumors as measured by RPPA with Poly E treatment compared to untreated controls, including down-regulation of PRAS40-pT246, Src-pY416, and MIG-6, and up-regulation of Notch1. This suggests that green tea compounds may act on alternative pathways in breast carcinogenesis.

Ki67 tumor expression as measured by IHC is a well-validated biomarker of clinical efficacy in phase 0 presurgical trials. Dowsett et al. studied changes in Ki67 in breast tumors as a pharmacodynamic biomarker of treatment response to tamoxifen and anastrozole in the preoperative setting, with short-term changes correlating with recurrence-free survival among women who continued these hormonal agents in the adjuvant setting [26]. However, the effects of short-term administration of non-hormonal agents in the presurgical setting are less clear $[27,28]$. In our study, Poly E did not significantly alter breast cancer proliferation, as measured by IHC or RPPA. Potential explanations for these findings include the lack of sufficient power to detect smaller effect sizes, the need for a longer drug intervention, or effects on alternative pathways not related to proliferation.

These negative Ki67 results are consistent with a randomized controlled trial of presurgical administration of Poly E $800 \mathrm{mg}$ daily for 3-6 weeks in 50 men undergoing radical prostatectomy for early stage prostate cancer [29]. The authors noted low to undetectable levels of green tea polyphenols in prostate tissue as a potential explanation for the non-significant results. However, two prostate cancer trials involving consumption of up to 6 cups of green tea daily in the presurgical setting demonstrated bioavailable levels of EGCG and other tea polyphenols in prostate tissue $[30,31]$.

We explored the effects of Poly E on growth factor signaling pathways relevant to breast cancer development. RPPA is a promising new technology that allows quantitative and simultaneous analysis of many components of a network. Furthermore, measuring protein levels, including post-translational modifications such as phosphorylation, is more representative of changes in pathway activity than measuring DNA or RNA levels [32]. Importantly, RPPA has been validated in protein extracted from FFPE tissue, requires only limited amounts of clinical material, and is ideal for measuring low abundance phosphorylated isoforms [21, 32-34]. We demonstrated significant correlation between tumor proliferation, ER, and PR expression by IHC and RPPA. In contrast to another study which showed high concordance between protein expression in core biopsies and surgical specimens [35], we observed significant changes in RPPA markers in the untreated control group. This may be due to an artifact of differences in tissue processing, such as fixation time. Of note, the tumor tissue from the Poly E-treated and control groups was processed in a similar fashion based upon standard clinical practice, therefore, the historical controls provide a useful reference group.

In breast cancer, EGCG has been shown to target transmembrane growth factor receptors, such as EGFR, HER2, c-MET, and IGF-1R with subsequent inhibition of downstream signaling pathways, such as the PI3K/AKT pathway. A number of studies have demonstrated the inhibitory effects of EGCG on the EGFR signaling pathway [36- 38]. EGCG also dose-dependently inhibited the growth of HER2/neu over-expressing breast cancer cell lines leading to a decrease in PI3K/AKT activity [39]. Li et al. identified IGF-1R as a high-affinity EGCG binding protein both in vitro and in vivo, with downstream inhibition of AKT activation [40]. Cardelli et al. demonstrated that treatment of the 
ER-negative breast cancer cell line, MDA-MB-231, and immortalized, nontumorigenic MCF10A cells with EGCG concentrations as low as $0.3 \mu \mathrm{M}$ (a level similar to that obtained by $400-800 \mathrm{mg}$ of EGCG in humans) completely blocked c-MET signaling and subsequent phosphorylation of AKT [6]. Molecular alterations in the PI3K/AKT pathway are considered the most frequent in breast cancer, encompassing over 30\% of invasive tumors [41]. Increased PI3K activity leads to activation of downstream signal transducers including AKT, mTOR, S6 kinase, and 4-EBP-1 [42]. These major pathways are responsible for increases in proliferation, survival, motility, invasion, and metastasis

PRAS40 (proline-rich Akt substrate of $40 \mathrm{kDa}$ )-pT246 is a substrate of AKT, which mediates the PI3K pathway, and over-expression of PRAS40 is implicated in several cancers. In an in vivo study, PRAS40 was expressed at higher levels in breast cancer cells compared to normal cells [43]. We observed significant down-regulation of PRAS40-pT246 in the Poly E group, as well as untreated controls. Although we observed significant modulation of other components in the PI3K/AKT pathway in the Poly E-treated group (Table 2), these did not reach statistical significance when compared to untreated controls.

MIG-6 (mitogen-inducible gene 6) is a tumor suppressor, which inhibits EGFR [44], and has reduced expression in breast tumors [45]. We observed a significant decrease in MIG-6 expression in breast tumor tissue after administration of Poly E compared to the control group, which may enhance tumorigenesis.

In the Src/STAT pathway, we also detected a decrease in Src (steroid receptor coactivator-1)-pY416 expression after Poly E treatment. Src-1 is phosphorylated through several post-translational pathways, including Src kinase and MAPK activity [46], and is expressed at relatively higher levels in breast cancer compared to normal breast tissue [47]. Therefore, down-regulation of SrcpY416 may inhibit tumorigenesis.

Finally, we demonstrated significant up-regulation of Notch1 in the Poly E-treated group, which is consistent with evidence from both in vitro and in vivo models. EGCG up-regulated the expression of Notch 1, which led to decreased proliferation and increased apoptosis in a significant time- and dose-dependent manner in colorectal cancer cell lines and in a mouse xenograft model [48]. However, Notch1 may also have oncogenic activity, through the promotion of the epithelial-to-mesenchymal transition, angiogenesis, and metastasis in human breast cancer cells [49]. Therefore, we observed protein biomarker changes after treatment with Poly E which may promote or inhibit breast carcinogenesis. These secondary endpoints are exploratory in nature and will need to be validated in a larger cohort.

Limitations of our study include the relatively small sample size and the higher than anticipated unevaluable rate. The majority of our patient population had endocrine-sensitive breast cancer, which limits our ability to evaluate the effects of Poly E in specific breast cancer subtypes, such as ER-negative tumors. Due to limited available tumor tissue, since $71 \%$ of participants had stage $0-\mathrm{I}$ disease, we were only able to confirm the RPPA changes by IHC for a limited number of proteins (Ki67, ER, PR, HER2) and we were unable to measure tissue levels of EGCG. However, prior phase I studies of Poly E $800 \mathrm{mg}$ daily for 4 weeks demonstrated a significant increase in systemic levels of free EGCG [9].
Unique strengths of our study include the use of a well-defined pharmaceutical-grade green tea extract and the analysis of serial tissue samples in the same subjects with untreated controls for comparison. A randomized double-blind study with a concurrent placebo control arm would have been a more rigorous study design, but using archived tumor tissue from matched historical controls provided a convenient reference group for biomarker comparisons with the Poly E-treated group. Furthermore, we utilized the high-throughput technology of RPPA to investigate potential drug mechanisms and target tissue effects of Poly E that may be relevant to breast carcinogenesis. Due to the exploratory nature of the RPPA markers, these findings need to be interpreted with caution.

Our trial represents one of the first studies in breast cancer patients to assess tissue biomarker changes following presurgical administration of Poly E. The clinical relevance of these biomarker changes will need to be confirmed in future studies. The goal with this presurgical phase 0 trial is to develop an efficient model for testing potential chemopreventive agents. Once a biological effect can be demonstrated using this study design, then subsequent chemoprevention trials with longer drug interventions can be pursued in breast cancer patients and high-risk women [50, 51].

\section{Acknowledgement and Declarations}

Funded by grant no. MRSG-08-021-01-CNE from the American Cancer Society.

The authors have no potential conflicts of interest to disclose.

\section{ClinicalTrials.gov Number: NCT00676793}

\section{References}

[1]. Fisher B, Costantino JP, Wickerham DL, Redmond CK, Kavanah M, et al (1998) Tamoxifen for prevention of breast cancer: report of the National Surgical Adjuvant Breast and Bowel Project P-1 Study. J Natl Cancer Inst 90: 1371-1388.

[2]. Vogel VG, Costantino JP, Wickerham DL, Cronin WM, Cecchini RS, et al (2006) Effects of tamoxifen vs raloxifene on the risk of developing invasive breast cancer and other disease outcomes: the NSABP Study of Tamoxifen and Raloxifene (STAR) P-2 trial. JAMA : the journal of the American Medical Association 295: 2727-2741.

[3]. Ogunleye AA, Xue F, Michels KB (2010) Green tea consumption and breast cancer risk or recurrence: a meta-analysis. Breast cancer research and treatment 119: 477-484.

[4]. Yang CS, Wang X, Lu G, Picinich SC (2009) Cancer prevention by tea: animal studies, molecular mechanisms and human relevance. Nat Rev Cancer 9: 429-439.

[5]. Stuart EC, Scandlyn MJ, Rosengren RJ (2006) Role of epigallocatechin gallate (EGCG) in the treatment of breast and prostate cancer. Life Sci 79: 2329-2336.

[6]. Bigelow RL, Cardelli JA (2006) The green tea catechins, (-)-Epigallocatechin-3-gallate (EGCG) and (-)-Epicatechin-3-gallate (ECG), inhibit HGF/ Met signaling in immortalized and tumorigenic breast epithelial cells. Oncogene 25: 1922-1930.

[7]. Thangapazham RL, Passi N, Maheshwari RK (2007) Green tea polyphenol and epigallocatechin gallate induce apoptosis and inhibit invasion in human breast cancer cells. Cancer biology \& therapy 6: 1938-1943.

[8]. Chang PY, Mirsalis J, Riccio ES, Bakke JP, Lee PS, et al (2003) Genotoxicity and toxicity of the potential cancer-preventive agent polyphenon E. Environ Mol Mutagen 41: 43-54.

[9]. Chow HH, Cai Y, Hakim IA, Crowell JA, Shahi F, et al (2003) Pharmacokinetics and safety of green tea polyphenols after multiple-dose administration of epigallocatechin gallate and polyphenon $\mathrm{E}$ in healthy individuals. Clin Cancer Res 9: 3312-3319.

[10]. Li N, Sun Z, Han C, Chen J (1999) The chemopreventive effects of tea on human oral precancerous mucosa lesions. Proc Soc Exp Biol Med 220: 
218-224.

[11]. Ahn WS, Yoo J, Huh SW, Kim CK, Lee JM, et al (2003) Protective effects of green tea extracts (polyphenon E and EGCG) on human cervical lesions. Eur J Cancer Prev 12: 383-390.

[12]. Bettuzzi S, Brausi M, Rizzi F, Castagnetti G, Peracchia G, Corti A (2006) Chemoprevention of human prostate cancer by oral administration of green tea catechins in volunteers with high-grade prostate intraepithelial neoplasia: a preliminary report from a one-year proof-of-principle study. Cancer Res 66: 1234-1240.

[13]. Shimizu M, Fukutomi Y, Ninomiya M, Nagura K, Kato T, et al (2008) Green tea extracts for the prevention of metachronous colorectal adenomas: a pilot study. Cancer Epidemiol Biomarkers Prev 17: 3020-3025.

[14]. Song S, Krishnan K, Liu K, Bresalier RS (2009) Polyphenon E inhibits the growth of human Barrett's and aerodigestive adenocarcinoma cells by suppressing cyclin D1 expression. Clin Cancer Res 15: 622-631.

[15]. Clarke RB, Laidlaw IJ, Jones LJ, Howell A, Anderson E (1993) Effect of tamoxifen on Ki67 labelling index in human breast tumours and its relationship to oestrogen and progesterone receptor status. Br J Cancer 67: 606-611.

[16]. Dowsett M, Smith IE, Ebbs SR, Dixon JM, Skene A, et al (2007) Prognostic value of Ki67 expression after short-term presurgical endocrine therapy for primary breast cancer. J Natl Cancer Inst 99: 167-170.

[17]. Hammond ME, Hayes DF, Dowsett M, Allred DC, Hagerty KL, et al (2010) American Society of Clinical Oncology/College Of American Pathologists guideline recommendations for immunohistochemical testing of estrogen and progesterone receptors in breast cancer. J Clin Oncol 28: 2784-2795.

[18]. Dowsett M, Nielsen TO, A'Hern R, Bartlett J, Coombes RC, et al (2011) Assessment of $\mathrm{Ki} 67$ in breast cancer: recommendations from the International Ki67 in Breast Cancer working group. J Natl Cancer Inst 103: 16561664

[19]. Tibes R, Qiu Y, Lu Y, Hennessy B, Andreeff M, et al (2006) Reverse phase protein array: validation of a novel proteomic technology and utility for analysis of primary leukemia specimens and hematopoietic stem cells. Molecular cancer therapeutics 5: 2512-2521.

[20]. Stemke-Hale K, Gonzalez-Angulo AM, Lluch A, Neve RM, Kuo WL, et al (2008) An integrative genomic and proteomic analysis of PIK3CA, PTEN, and AKT mutations in breast cancer. Cancer research 68: 6084-6091.

[21]. Guo H, Liu W, Ju Z, Tamboli P, Jonasch E, et al (2012) An efficient procedure for protein extraction from formalin-fixed, paraffin-embedded tissues for reverse phase protein arrays. Proteome Sci 10: 56.

[22]. Hennessy BT, Lu Y, Gonzalez-Angulo AM, Carey MS, Myhre S, et al (2010) A Technical Assessment of the Utility of Reverse Phase Protein Arrays for the Study of the Functional Proteome in Non-microdissected Human Breast Cancers. Clin Proteomics 6: 129-151.

[23]. Quackenbush J (2002) Microarray data normalization and transformation. Nat Genet 32 Suppl:496-501.

[24]. Hu J, He X, Baggerly KA, Coombes KR, Hennessy BT, Mills GB (2007) Non-parametric quantification of protein lysate arrays. Bioinformatics 23: 1986-1994.

[25]. Raghav KP, Wang W, Liu S, Chavez-MacGregor M, Meng X, et al (2012) cMET and phospho-cMET protein levels in breast cancers and survival outcomes. Clin Cancer Res 18: 2269-2277.

[26]. Dowsett M, Smith IE, Ebbs SR, Dixon JM, Skene A, et al (2005) Short-term changes in Ki-67 during neoadjuvant treatment of primary breast cancer with anastrozole or tamoxifen alone or combined correlate with recurrencefree survival. Clin Cancer Res 11: 951s-958s.

[27]. Niraula S, Dowling RJ, Ennis M, Chang MC, Done SJ, et al (2012) Metformin in early breast cancer: a prospective window of opportunity neoadjuvant study. Breast Cancer Res Treat 135: 821-830.

[28]. Bonanni B, Puntoni M, Cazzaniga M, Pruneri G, Serrano D, et al (2012) Dual effect of metformin on breast cancer proliferation in a randomized presurgical trial. J Clin Oncol 30: 2593-2600.

[29]. Nguyen MM, Ahmann FR, Nagle RB, Hsu CH, Tangrea JA, et al (2012) Randomized, double-blind, placebo-controlled trial of polyphenon $\mathrm{E}$ in prostate cancer patients before prostatectomy: evaluation of potential chemopreventive activities. Cancer prevention research 5: 290-298.

[30]. Henning SM, Aronson W, Niu Y, Conde F, Lee NH, et al (2006) Tea polyphenols and theaflavins are present in prostate tissue of humans and mice after green and black tea consumption. J Nutr 136: 1839-1843.

[31]. Wang P, Aronson WJ, Huang M, Zhang Y, Lee RP, et al (2010) Green tea polyphenols and metabolites in prostatectomy tissue: implications for cancer prevention. Cancer Prev Res (Phila) 3: 985-993.

[32]. Espina V, Woodhouse EC, Wulfkuhle J, Asmussen HD, Petricoin EF, 3rd, Liotta LA (2004) Protein microarray detection strategies: focus on direct detection technologies. Journal of immunological methods 290: 121-133.

[33]. Liotta LA, Espina V, Mehta AI, Calvert V, Rosenblatt K, et al (2003) Protein microarrays: meeting analytical challenges for clinical applications. Cancer Cell 3: 317-325.

[34]. Berg D, Hipp S, Malinowsky K, Bollner C, Becker KF (2010) Molecular profiling of signalling pathways in formalin-fixed and paraffin-embedded cancer tissues. Eur J Cancer 46: 47-55.

[35]. Berg D, Langer R, Tran K, Walch A, Schuster T, et al (2011) Protein microarray-based comparison of HER2, estrogen receptor, and progesterone receptor status in core biopsies and surgical specimens from FFPE breast cancer tissues. Appl Immunohistochem Mol Morphol 19: 300-305.

[36]. Hou Z, Sang S, You H, Lee MJ, Hong J, et al (2005) Mechanism of action of (-)-epigallocatechin-3-gallate: auto-oxidation-dependent inactivation of epidermal growth factor receptor and direct effects on growth inhibition in human esophageal cancer KYSE 150 cells. Cancer Res 65: 8049-8056.

[37]. Shimizu M, Deguchi A, Lim JT, Moriwaki H, Kopelovich L, Weinstein IB (2005) (-)-Epigallocatechin gallate and polyphenon E inhibit growth and activation of the epidermal growth factor receptor and human epidermal growth factor receptor-2 signaling pathways in human colon cancer cells. Clin Cancer Res 11: 2735-2746.

[38]. Adachi S, Nagao T, To S, Joe AK, Shimizu M, et al (2008) (-)-Epigallocatechin gallate causes internalization of the epidermal growth factor receptor in human colon cancer cells. Carcinogenesis 29: 1986-1993.

[39]. Masuda M, Suzui M, Lim JT, Weinstein IB (2003) Epigallocatechin-3-gallate inhibits activation of HER-2/neu and downstream signaling pathways in human head and neck and breast carcinoma cells. Clin Cancer Res 9: 3486-3491.

[40]. Li M, He Z, Ermakova S, Zheng D, Tang F, Cho YY, et al (2007) Direct inhibition of insulin-like growth factor-I receptor kinase activity by (-)-epigallocatechin-3-gallate regulates cell transformation. Cancer Epidemiol Biomarkers Prev 16: 598-605.

[41]. Engelman JA, Luo J, Cantley LC (2006) The evolution of phosphatidylinositol 3-kinases as regulators of growth and metabolism. Nat Rev Genet 7: 606-619.

[42]. Keniry M, Parsons R (2008) The role of PTEN signaling perturbations in cancer and in targeted therapy. Oncogene 27: 5477-5485.

[43]. Huang B, Porter G (2005) Expression of proline-rich Akt-substrate PRAS40 in cell survival pathway and carcinogenesis. Acta pharmacologica Sinica 26: 1253-1258.

[44]. Ferby I, Reschke M, Kudlacek O, Knyazev P, Pante G, et al (2006) Mig6 is a negative regulator of EGF receptor-mediated skin morphogenesis and tumor formation. Nature medicine 12: 568-573.

[45]. Anastasi S, Sala G, Huiping C, Caprini E, Russo G, et al (2005) Loss of RALT/MIG-6 expression in ERBB2-amplified breast carcinomas enhances ErbB-2 oncogenic potency and favors resistance to Herceptin. Oncogene 24: 4540-4548.

[46]. Walsh CA, Qin L, Tien JC, Young LS, Xu J (2012) The function of steroid receptor coactivator- 1 in normal tissues and cancer. International journal of biological sciences 8: 470-485.

[47]. Zhang Y, Duan C, Bian C, Xiong Y, Zhang J (2013) Steroid receptor coactivator-1: A versatile regulator and promising therapeutic target for breast cancer. Journal of Steroid Biochemistry \& Molecular Biology 138: 17-23.

[48]. Jin H, Gong W, Zhang C, Wang S (2013) Epigallocatechin gallate inhibits the proliferation of colorectal cancer cells by regulating Notch signaling. OncoTargets and therapy 6:145-153.

[49]. Leong KG, Niessen K, Kulic I, Raouf A, Eaves C, et al (2007) Jagged1mediated Notch activation induces epithelial-to-mesenchymal transition through Slug-induced repression of E-cadherin. The Journal of experimental medicine 204: 2935-2948.

[50]. Crew KD, Brown P, Greenlee H, Bevers TB, Arun B, et al (2012) Phase IB randomized, double-blinded, placebo-controlled, dose escalation study of polyphenon $\mathrm{E}$ in women with hormone receptor-negative breast cancer. Cancer Prev Res (Phila) 5: 1144-1154.

[51]. Wu AH, Spicer D, Stanczyk FZ, Tseng CC, Yang CS, Pike MC (2012) Effect of 2-month controlled green tea intervention on lipoprotein cholesterol, glucose, and hormone levels in healthy postmenopausal women. Cancer Prev Res (Phila) 5: 393-402. 